\title{
INCIDENCE OF TRICHOMOMAS VAGINALIS IN IRELAND: Are we testing the right target population?
}

\author{
Authors: Allison Waters, Christina Byrne, Suzie Coughlan, Cillian De Gascun \\ Affiliation: UCD National virus Reference Laboratory, Belfield Campus, Dublin 4, IRELAND
}

\section{INTRODUCTION}

- Trichomonas vaginalis (TV) is the most prevalent non-viral sexually transmitted disease. It is estimated that $>250$ million individuals are infected each year globally. However, there are vast differences in the reported incidence for each continent.

- Testing is recommended for symptomatic women, women $>35$ years, and those who have had sexual contact with a TV positive individual.

- Over $90 \%$ of TV cases are diagnosed in women.

\section{AIM: ESTIMATE THE INCIDENCE OF TRICHOMONAS VAGINALIS IN AN IRISH POPULATION.}

FIGURE 2. Trichomonas vaginalis detection per age group
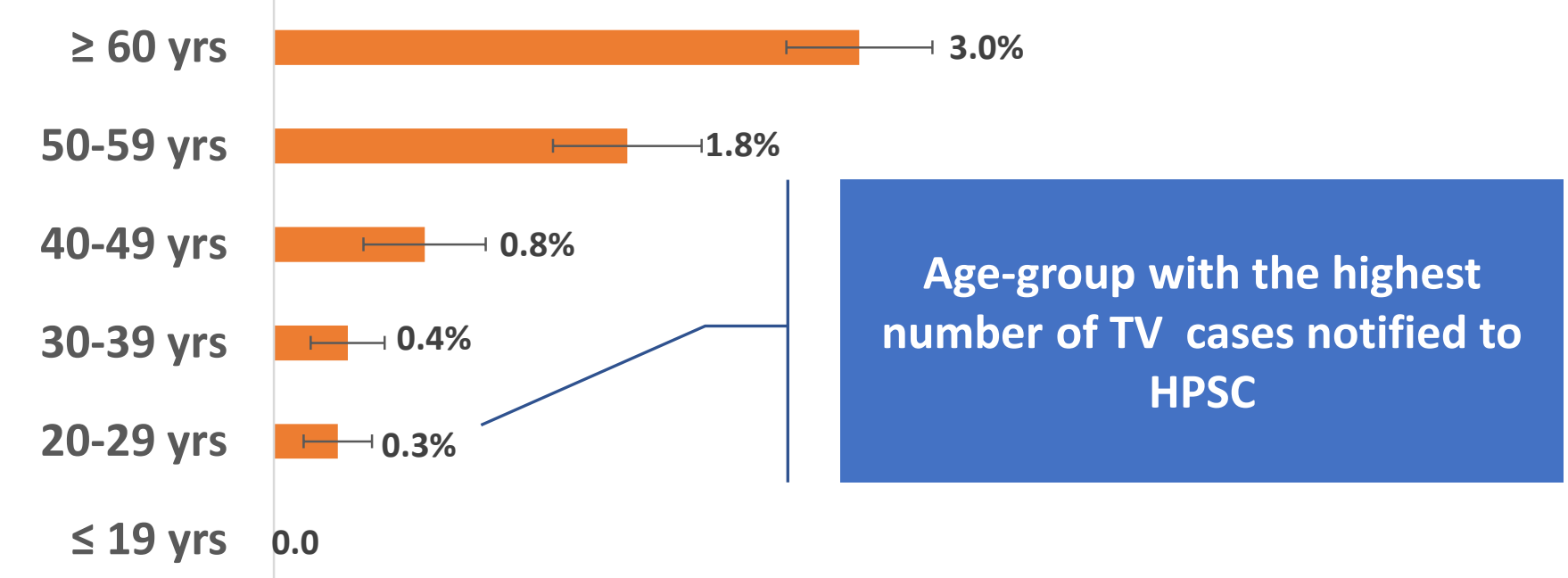

FIGURE 3. Specimen received for testing with detectable Trichomonas vaginalis

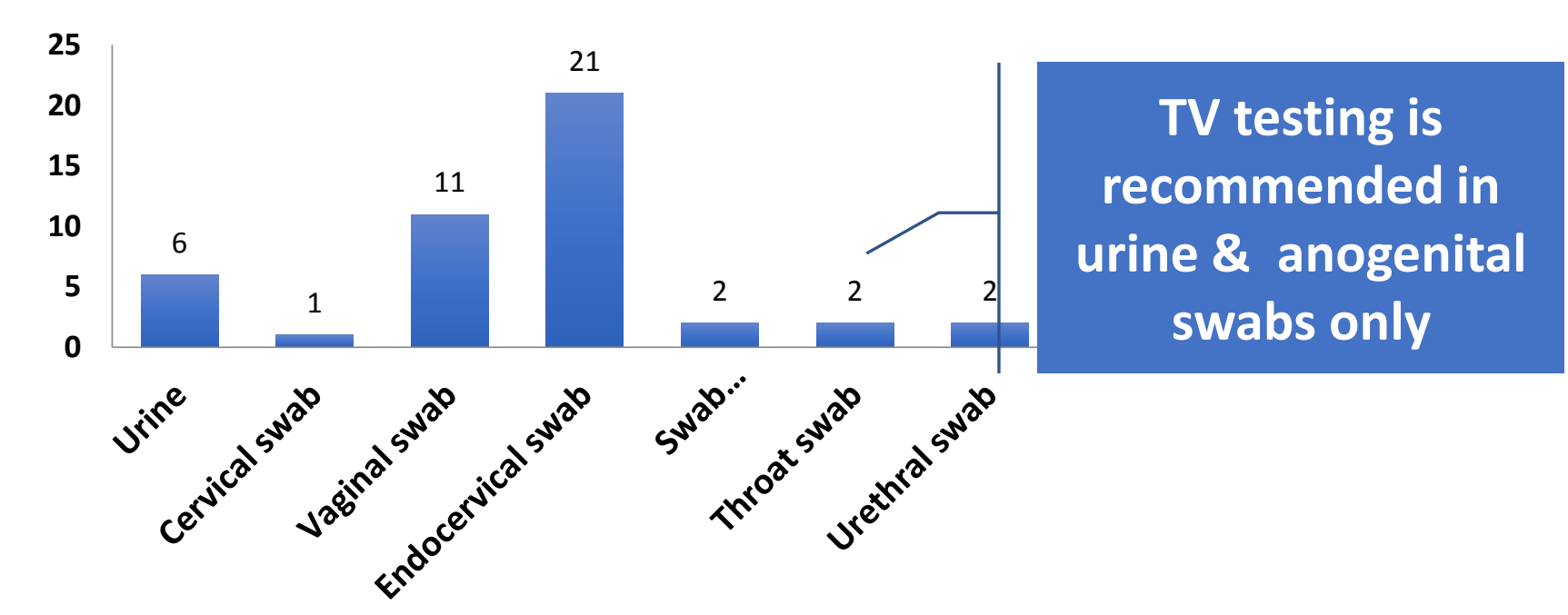

FIGURE 1. Summary of study methodology

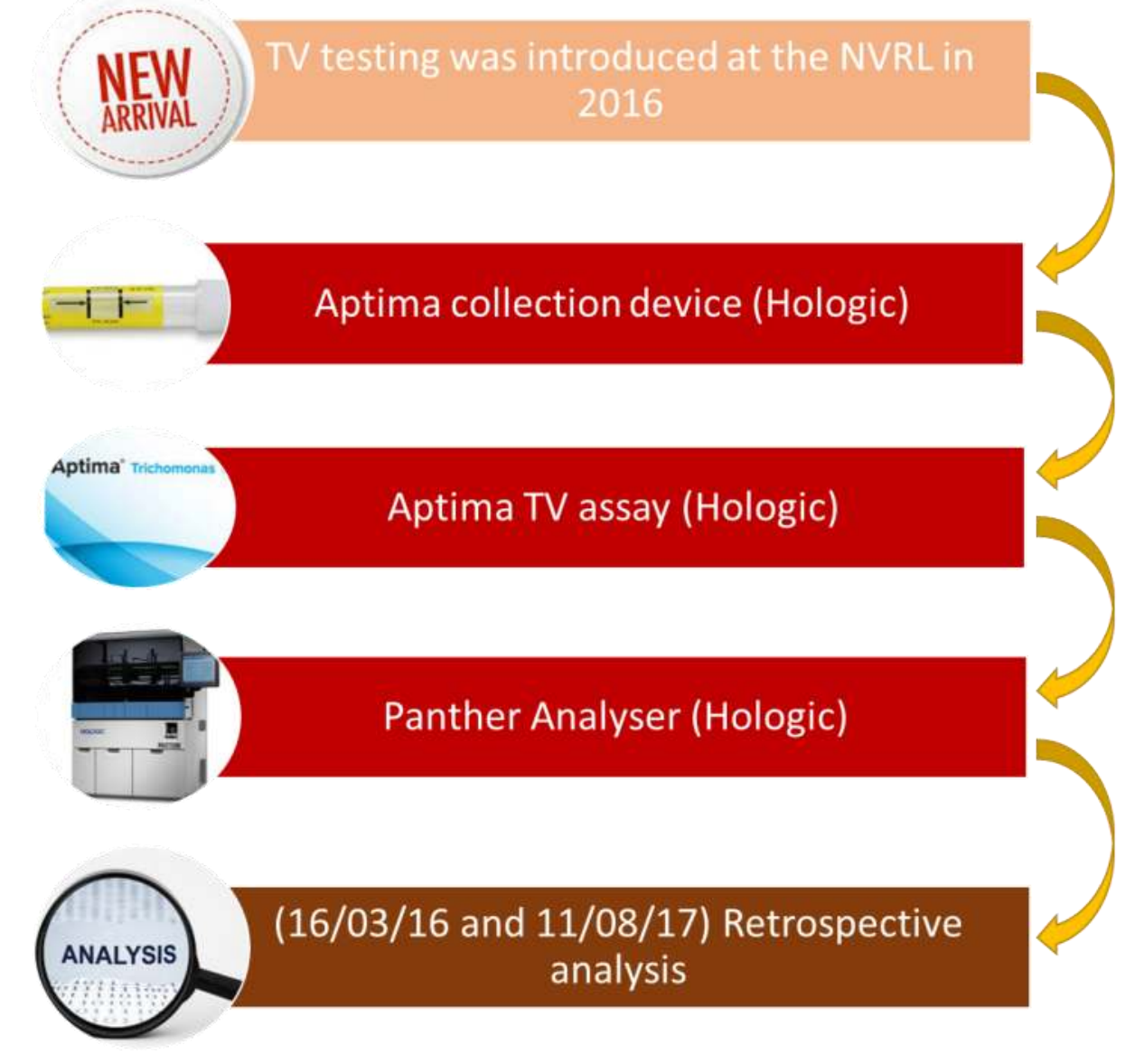

\section{RESULTS}

- A detection rate of $0.4 \%$ was estimated. 9933 patients were screened for the presence of TV during the 18month study timeframe.

- As expected, an increasing TV detection rate correlated with increasing age in the patients screened, and was a high as $3 \%$ in women $>65$ years of age

\begin{tabular}{|l|c|c|c|c|}
\hline \multirow{2}{*}{ TV result } & \multicolumn{2}{|c|}{ Female } & \multicolumn{2}{c|}{ Male } \\
\cline { 2 - 6 } & $\mathrm{N}=$ & $\begin{array}{c}\text { Median } \\
\text { age }(\mathrm{yrs})\end{array}$ & $\mathrm{N}=$ & $\begin{array}{c}\text { Median } \\
\text { age }(\mathrm{yrs})\end{array}$ \\
\hline Detected & 36 & 36.3 & 4 & 33.6 \\
\hline Not Detected & 8155 & 29.3 & 1711 & 31.8 \\
\hline
\end{tabular}

\section{TAKE HOME MESSAGES ...}

- The TV incidence was lower than expected compared with other European countries

- The present study showed an increasing TV detection rate with increasing age, ranging from $0.3 \%$ in the $20-29$ years age bracket to $3 \%$ in women $>65$ years of age.

- TV notifications in Ireland are highest for women in the 20-29 age bracket, seemingly in direct contrast with the increasing incidence rate for older women calculated by the present study.

- This data indicate that younger women are being opportunistically screened for TV as part of routine STI testing.

- A more targeted approach to TV testing is required to increase uptake in the testing of older women. 